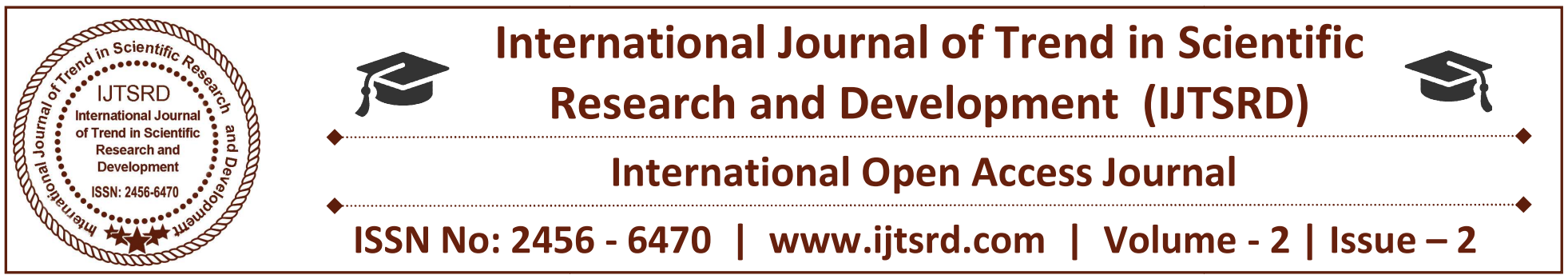

\title{
Formulation and In Vitro Evaluation of Floating Effervescent Tablets of Levodropropizine
}

\author{
Arshiya Jabeen \\ Warangal, Telangana, India
}

\begin{abstract}
The present study is the development of Hydrodynamically Balanced Systems (HBS) of Levodropropizine, an antitussive agent, which are designed to increase the gastric residence time, thus prolonging the drug release. Levodropropizine HBS were prepared by using various viscosity grades of hydroxypropyl methylcellulose $\left(\mathrm{K}_{4} \mathrm{M}, \mathrm{K}_{15} \mathrm{M}, \mathrm{K}_{100} \mathrm{M}\right)$ by Direct compression technique. The prepared HBS tablets were evaluated for various physical characteristics and optimized formulation was identified. Formulation F3 prepared with HPMC K ${ }_{4} \mathrm{M}$ showed results by releasing $97.14 \pm$ SD of drug in 24 $\mathrm{h}$ in a controlled manner with a floating lag time of 4 sec and total floating time of $24 \mathrm{~h}$ has been considered as an optimized formulation. Regression analysis of drug dissolution profiles on the basis of Higuchi and Korsmeyer model, indicated that diffusion is the predominant mechanism controlling the drug release.
\end{abstract}

Keywords: Levodropropizine, Hydrodynamically Balanced Systems, Hydroxy Propyl Methyl Cellulose, In vitro floating

\section{INTRODUCTION:}

Oral delivery of drugs is by far the most preferable route of drug delivery due to the Ease of administration, patient compliance and flexibility in formulation etc. Effective oral drug delivery may depend upon the factors such as gastric emptying process, gastrointestinal transit time of dosage form, drug release from the dosage form and site of absorption of drugs (Sanjay, 2003).
The drug therapeutic indices could be maximized while indices of adverse reactions or side effects could be minimized by regulating the drug release in body in a well-defined controlled manner. This would eliminate the haphazard and uncontrolled blood plasma profiles of drugs usually associated with conventional dosage forms (Aulton, 2002).

Most of the oral dosage forms possess several physiological limitations such as variable gastrointestinal transit, because of variable gastric emptying leading to non-uniform absorption profiles, incomplete drug release and shorter residence time of the dosage form in the stomach. This leads to incomplete absorption of drugs having absorption window especially in the upper part of the small intestine, as once the drug passes down the absorption site, the remaining quantity goes unabsorbed (Rouge et al., 1996).

To overcome this limitation, oral gastro retentive dosage forms are developed. Gastro retentive dosage forms (GRDFs), extend significantly the period of time over which the drug may be released. Thus, they not only prolong dosing intervals, but also increase patient compliance beyond the level of existing controlled release dosage forms. Gastro retentive systems can remain in the gastric region for several hours and hence significantly prolong the gastric residence time of drugs. Prolonged gastric retention improves bioavailability, reduces drug waste, and improves solubility for drugs that are less soluble in a high $\mathrm{pH}$ environment. 
The controlled gastric retention of solid dosage forms may be achieved by the mechanisms of mucoadhesion, flotation, sedimentation, expansion, modified shape system or by the simultaneous administration of pharmacological agent that delay gastric empty (Shweta et al., 2005).

The identification of new diseases and the resistance shown towards the existing drugs called for the introduction of new therapeutic molecules. In response, a large number of chemical entities have been introduced, of which some have absorption all over the gastrointestinal tract, some have absorption windows, especially the upper part of the small intestine and some drugs have poor solubility in intestinal media. The drugs belonging to the second and third categories, and the drugs which are required for local action in the stomach, require a specialized delivery system. All the above requirements can be met and effective delivery of the drugs to the absorption window, for local action and for the treatment of gastric disorders such as gastroesophageal reflux, can be achieved by floating drug delivery systems (Reddy et al., 2002).

The various buoyant compositions include hollow microspheres, granules, powders, capsules, tablets (pills), and laminated films. Most of the floating systems include single unit systems, such as HBS and floating tablets (Sangekar et al., 1987).

These systems are unreliable and irreproducible in prolonging residence time in stomach when orally administered due to their 'all or nothing' emptying process. On the other hand, multiple unit dosage forms appear to be effective in reducing inter subject variability and lower the probability of dose dumping. It has been observed that only hydrophilic polymers are not sufficient for floating characteristics and better results are possible with use of some soluble or gasevolving excipients (Hiton et al., 1992), the release rate was directly proportional to viscosity and concentration of the polymer used (Stockwell, 1986).

\section{MATERIALS AND METHODS:}

Materials: Levodropropizine was received as a gift sample from Euro drugs private limited, Hyderabad. The polymers $\mathrm{HPMC}_{\mathrm{K} 4} \mathrm{M}$, HPMC $\mathrm{K}_{15} \mathrm{M}$ and $\mathrm{HPMC}$ $\mathrm{K}_{100} \mathrm{M}$ were received as a gift samples from Hetero laboratories, Hyderabad. Lactose monohydrate was obtained from MSN laboratories, Hyderabad. Sodium bicarbonate was obtained from Sun pharma laboratories. Citric acid was obtained from AET laboratories. polyvinylpyrrolidine k 30 (pvp k 30), magnesium stearate and talc were obtained from Hetero laboratories, Hyderabad. All the chemicals and reagents required for the present experimental work are of analytical grade.

\section{Formulation of Floating controlled release tablets of Levodropropizine :}

Floating effervescent tablets containing Levodropropizine was prepared by direct compression technique using different concentrations of HPMC $\mathrm{K}_{4} \mathrm{M}$, HPMC $\mathrm{K}_{15} \mathrm{M}$ and $\mathrm{HPMC} \mathrm{K}_{100} \mathrm{M}$ with sodium bicarbonate and citric acid as gas generating agents.

Accurately weighed quantities of polymer and lactose, PVP k 30 were taken in a mortar and mixed geometrically. To this required quantity of drug (180mg) was added and mixed slightly with pestle. Accurately weighed quantity of sodium bicarbonate and citric acid was taken separately in a mortar and powdered with pestle. The powder is passed through sieve no 40 and mixed with the drug blend, which is also passed through sieve no 40 . The whole mixture was collected in a plastic bag \& mixed for $3 \mathrm{~min}$. To this magnesium stearate, talc was added and mixed for $5 \mathrm{~min}$. The mixture equivalent to $380 \mathrm{mg}$ was compressed into tablets with $10 \mathrm{~mm}$ flat round punches. The compositions of all the formulations are given in Table 1. 
International Journal of Trend in Scientific Research and Development (IJTSRD) ISSN: 2456-6470

Table 1: Composition of floating effervescent tablets of levodropropizine

\begin{tabular}{|c|c|c|c|c|c|c|c|c|c|c|}
\hline \multirow{2}{*}{ INGREDIENTS } & \multicolumn{9}{|c|}{ FORMULA TIONS (mg) } \\
\hline Levodropropizine & 180 & 180 & 180 & 180 & 180 & 180 & 180 & 180 & 180 & 180 \\
\hline HPMC K 4 M & 50 & 75 & 100 & - & - & - & - & - & - & 25 \\
\hline HPMC K $_{15} \mathrm{M}$ & - & - & - & 50 & 75 & 100 & - & - & - & 25 \\
\hline HPMC K ${ }_{100} \mathrm{M}$ & - & - & - & - & - & - & 50 & 75 & 100 & 25 \\
\hline Lactose monohydrate & 60 & 35 & 10 & 60 & 35 & 10 & 60 & 35 & 10 & 35 \\
\hline Sodium bicarbonate & 50 & 50 & 50 & 50 & 50 & 50 & 50 & 50 & 50 & 50 \\
\hline Citric acid & 20 & 20 & 20 & 20 & 20 & 20 & 20 & 20 & 20 & 20 \\
\hline PVP k 30 & 15 & 15 & 15 & 15 & 15 & 15 & 15 & 15 & 15 & 15 \\
\hline Magnesium stearate & 3 & 3 & 3 & 3 & 3 & 3 & 3 & 3 & 3 & 3 \\
\hline Talc & 2 & 2 & 2 & 2 & 2 & 2 & 2 & 2 & 2 & 2 \\
\hline Total weight & 380 & 380 & 380 & 380 & 380 & 380 & 380 & 380 & 380 & 380 \\
\hline
\end{tabular}

\section{PHYSICOCHEMICAL EVALUATION OF INTRAGASTRIC BUOYANT TABLETS :}

\section{PRE - COMPRESSION PARAMETERS:}

Angle of Repose: The fixed funnel method was employed to measure the angle of repose. A funnel was secured with its tip at a given height ' $h$ ' above a graph paper that was placed on a flat horizontal surface. The blend was carefully pored through the funnel until the apex of the conical pile just touched the tip of the funnel. The radius, $r$ of the base of the conical pile was measured. The angle of repose, $\alpha$, was calculated using the following formula (Copper et al., 1986).

$$
A=\tan ^{-1} h / r
$$

Bulk Density: Required quantity of material was passed through a sieve no. 25 to break up agglomerates and introduced into a dry $100 \mathrm{ml}$ cylinder. Without compacting, the powder was carefully leveled and the unsettled apparent volume (Vo) was read. The bulk density was calculated in grams per ml using the formula (Shah et al., 1997).

$$
\text { Bulk density }=(M) /\left(V_{0}\right)
$$

Tapped Density: After carrying out the procedure as given in the measurement of bulk density the cylinder containing the sample was tapped using a mechanical tapped density tester that provides a fixed drop of 14 $\pm 2 \mathrm{~mm}$ at a nominal rate of 300 drops per min. The cylinder was tapped 500 times initially followed by an additional tap of 750 times and then tapped volume $V_{f}$ was measured to the nearest graduated unit. The tapped density was calculated in $\mathrm{g} / \mathrm{ml}$, using the formula:

\section{Tapped density $=(\mathbf{M}) /\left(V_{f}\right)$}

Carr's index: Carr's developed an indirect method of measuring powder flow from bulk densities. The percentage compressibility of a powder was a direct measure of the potential powder arch or bridge strength and stability. Carr's index of each formulation was calculated to equation given below:

$\%$ Compressibility Index $=(\mathrm{Vr}-\mathrm{Vo}) * 100 / \mathrm{Vr}$ 
Hausners ratio: The Hausner ratio is a number that is correlated to the flowability of a powder or granular material and measured by the ratio of tapped density to bulk density.

$$
\text { Hausner Ratio }=V_{0} / V_{f}
$$

\section{POST - COMPRESSION PARAMETERS:}

Tablet density : Tablet density is an important parameter for floating tablets. The tablet will float when its density is less than that of $0.1 \mathrm{~N} \mathrm{HCl}$ $(1.004 \mathrm{~g} / \mathrm{cc})$.

Hardness: This test is used to check the hardness of a tablet which may undergo chipping or breakage during storage, transportation and handling. In this five tablets were selected at random and the hardness of each tablet was measured with hardness tester.

Friability: Friability is the loss of weight of tablet in the container/package, due to removal of fine particles from the surface. In this process quality control test is performed to ensure the ability of tablets to withstand the shocks during processing, handling, transportation, and shipment. Permitted friability limit is $1.0 \%$. Roche friabilator was used to measure the friability of the tablets. Ten tablets were weighed collectively and placed in the chamber of the friabilator. In the friabilator, the tablets were exposed to rolling, resulting free fall of tablets. It was rotated at a rate of $25 \mathrm{rpm}$. After 100 rotations $(4 \mathrm{~min})$, the tablets were taken out from the friabilator and intact tablets were again weighed collectively. The percent friability was determined using the following formula :

$$
F=(1-W / W o) \times 100
$$

where, $\mathrm{W}=$ Initial weight

Wo $=$ Final weight

Uniformity of weight: Randomly selected 20 tablets were weighed individually and together in a single pan balance. The average weight was noted and standard deviation was calculated. The tablet passes the test if not more than two tablets fall outside the percentage limit and none of the tablet differs by more than double percentage limit.

Swelling characteristics (Water uptake study): The swelling properties of HPMC matrices containing drug were determined by placing the tablet matrices in the dissolution test apparatus, in $900 \mathrm{ml}$ of $0.1 \mathrm{~N} \mathrm{HCl}$ at $37 \pm 0.5^{\circ} \mathrm{C}$. The tablets were removed periodically from dissolution medium. After draining free from water by blotting paper, these were measured for weight gain. Swelling characteristics were expressed in terms of percentage water uptake (WU\%) show relationship between swelling index and time.

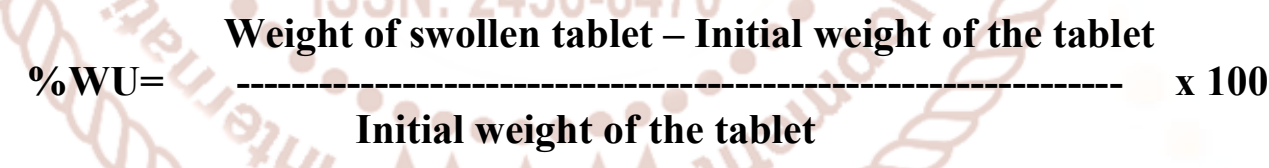

In vitro buoyancy studies : The in vitro buoyancy was determined by floating lag time. The tablets were placed in an $100 \mathrm{ml}$ beaker containing $0.1 \mathrm{~N} \mathrm{HCl}$. The time required for the tablet to rise to the surface and float was determined as floating lag time (FLT). The duration of time for which the dosage form constantly remained on the surface of medium was determined as the total floating time (TFT).

Uniformity of drug content: Five tablets were powdered in a glass mortar and $100 \mathrm{mg}$ of powder was placed in a $100 \mathrm{ml}$ stoppered conical flask. The drug was extracted with $0.1 \mathrm{~N} \mathrm{HC1}$ with vigorous shaking on a mechanical gyratory shaker (100 rpm) for $5 \mathrm{~h}$ and filtered into $50 \mathrm{ml}$ volumetric flask through cotton wool and filtrate was made up to the mark by passing more $0.1 \mathrm{~N}$ HCI through filter, further appropriate dilution were made and absorbance was measured at $239 \mathrm{~nm}$ against blank.

In vitro dissolution studies: In vitro dissolution studies of HBS of Levodropropizine were carried out using USP XXIII tablet dissolution test apparatus-II, employing a paddle stirrer at $50 \mathrm{rpm}$ using $900 \mathrm{ml}$ of $0.1 \mathrm{~N} \mathrm{HC1}$ for $24 \mathrm{~h}$ at $37 \pm 0.5^{\circ} \mathrm{C}$ as dissolution medium. One tablet was used in each test. At predetermined time intervals, $5 \mathrm{ml}$ of the samples were withdrawn by means of a syringe fitted with a pre filter. The volume withdrawn at each interval was replaced with same quantity of fresh dissolution medium maintained at $37 \pm 0.5^{\circ} \mathrm{C}$. The samples were analyzed for drug release by measuring the 
absorbance at $239 \mathrm{~nm}$ using UV-Visible spectrophotometer after suitable dilutions.

\section{DRUG RELEASE KINETICS:}

To analyze the mechanism of drug release from the prepared formulations, the data obtained from in vitro release studies were subjected to Zero order kinetics, First order kinetics, Higuchi model, Erosion equation, Korsmeyer-peppas model. (Peppas et al., 1980, Higuchi et al., 1963, and Bamba et al., 1979).

Zero order release kinetics: It defines a linear relationship between the fractions of drug release vs times.

$$
\mathbf{Q}=\mathbf{k}_{\mathbf{0}} \mathbf{t}
$$

A plot of fraction of drug release against time will be linear, if the release obeys Zero Order release kinetics.

First order release kinetics: This type of model to analyze drug dissolution study was first proposed by Gibaldi and Feldman and later by Wagner. The relation expressing this model:

$$
\log Q_{t}=\log Q_{0}+K_{1} t / 2.303
$$

In this way a graphical relationship between log percent drug remaining versus time to get the First order constant from the slope.

Higuchi equation: It defines a linear dependence of the active fraction released per unit of surface $(\mathrm{Q})$ on the surface root of time.

$$
\mathbf{Q}=\mathbf{K}^{2} \mathbf{t} 1 / 2
$$

A plot of the fraction of drug released against root of time will the linear if the release obeys Higuchi Equation. This equation describes drug release as a diffusion process based on the Flick's Law Square root time dependent.

Erosion Equation: This equation defines the drug release based on tablet erosion alone.

$$
Q=1-\left(1-K^{3} t\right)^{3}
$$

Thus, a plot between [1-(1 - Q)1/3] against time will be linear if the release obeys erosion equation.

Peppas \& korsemeyer equation: In order to define a model, which would represent a better fit for the formulation dissolution data was further analyzed by Peppas \& Korsemeyer equation.

\section{Mt $\backslash M \alpha=$ K.tn}

To characterize the mechanism for both solvent penetration and drug release ' $n$ ' can be used as abstracted. A plot between log of $\mathrm{Mt} \backslash \mathrm{M} \alpha$ against log of time will be linear if the release obeys Peppas \& Korsmeyer equation and the slope of this plot represents $n$ value.

\section{Stability Studies:}

The promising formulation was tested for a period of 8 weeks at different temperatures of $25^{\circ} \mathrm{C} \& 40^{\circ} \mathrm{C}$ with $60 \% \mathrm{RH} \& 75 \% \mathrm{RH}$, for their drug content.

\section{RESULTS AND DISCUSSIONS:}

Effect of hydrophilic polymers applied on formulations was assessed. In the present work ten formulations were prepared.

\section{EVALUATION OF INTRAGASTRIC BUOYANT TABLET FORMULATION:}

Pre-compression parameters: Results of the precompression parameters performed on the blend for batch F1 to F10 are tabulated in Table 2.

The bulk density and the tapped density for all the formulations varied from $0.3082 \pm 0.06$ to $0.4416 \pm$ $0.06 \mathrm{~g} / \mathrm{ml}$ and $0.3550 \pm 0.08$ to $0.4927 \pm 0.04 \mathrm{~g} / \mathrm{ml}$ respectively. The percentage compressibility of powder was determined using compressibility index. Carr's index lies within the range of 10.3 to $13.08 \%$. All the formulations show good compressibility. Angle of repose of all the formulations was found to be less than $30^{\circ}$, which indicates a good flow property of the powders. The values were found to be in the range of $21^{\circ} 36^{\prime} \pm 0.15$ to $28^{\circ} 06^{\prime} \pm 0.18$. Hausner ratio was found to be in the range 1.11 to 1.16 . 
International Journal of Trend in Scientific Research and Development (IJTSRD) ISSN: 2456-6470

Table 2: Evaluation of Pre-compression Parameters

\begin{tabular}{|c|c|c|c|c|c|}
\hline $\begin{array}{c}\text { Batch } \\
\text { code }\end{array}$ & Angle of repose & $\begin{array}{c}\text { Bulk density } \\
(\mathrm{g} / \mathrm{ml})\end{array}$ & $\begin{array}{c}\text { Tapped density } \\
(\mathrm{g} / \mathrm{ml})\end{array}$ & $\begin{array}{c}\text { Carr's } \\
\text { Index (\%) }\end{array}$ & $\begin{array}{c}\text { Hausner } \\
\text { Ratio }\end{array}$ \\
\hline F1 & $24.20 \pm 0.12$ & $0.4031 \pm 0.05$ & $0.4581 \pm 0.03$ & 11.9 & 1.13 \\
\hline F2 & $26.17 \pm 0.14$ & $0.3908 \pm 0.04$ & $0.3858 \pm 0.05$ & 11.6. & 1.13 \\
\hline F3 & $28.06 \pm 0.18$ & $0.3082 \pm 0.06$ & $0.3550 \pm 0.08$ & 13.1 & 1.15 \\
\hline F4 & $25.05 \pm 0.13$ & $0.3825 \pm 0.03$ & $0.4366 \pm 0.04$ & 12.3 & 1.14 \\
\hline F5 & $26.76 \pm 0.17$ & $0.4034 \pm 0.02$ & $0.4581 \pm 0.02$ & 11.9 & 1.13 \\
\hline F6 & $21.36 \pm 0.15$ & $0.4083 \pm 0.01$ & $0.4696 \pm 0.04$ & 13.05 & 1.15 \\
\hline F7 & $21.96 \pm 0.14$ & $0.3932 \pm 0.08$ & $0.4562 \pm 0.06$ & 13.08 & 1.16 \\
\hline F8 & $26.76 \pm 0.11$ & $0.4412 \pm 0.05$ & $0.4923 \pm 0.04$ & 10.3 & 1.11 \\
\hline F9 & $24.08 \pm 0.15$ & $0.4416 \pm 0.06$ & $0.4927 \pm 0.04$ & 10.37 & 1.11 \\
\hline F10 & $26.76 \pm 0.18$ & $0.3996 \pm 0.04$ & $0.3562 \pm 0.06$ & 12.4 & 1.14 \\
\hline
\end{tabular}

Post-compression parameters: The formulated tablets were subjected for post-compressional evaluation such as thickness, hardness, weight variation, friability, drug content, invitro buoyancy studies, swelling studies, invitro dissolution studies and stability studies. Tablet thickness $(n=3)$ were almost uniform in all the formulations and values for tablets ranged from $3.37 \pm 0.03$ to $3.53 \pm 0.04 \mathrm{~mm}$. The hardness of all formulations was in the range of $4.5 \pm 0.01$ to $5.7 \pm 0.06 \mathrm{~kg} / \mathrm{cm}^{2}$, indicating satisfactory mechanical strength. The weight variation values of tablets ranged from $374 \pm 5 \%$ to $380 \pm 5$
$\%$. All the tablets passed weight variation test as the $\%$ weight variation was within the Pharmacopoeias limits of $\pm 7.5 \%$ of the weight. The friability values ranged from $0.23 \pm 0.01$ to $0.67 \pm 0.06$. All the values are below $1 \%$ indicating that the tablets of all formulations are having good compactness and showing enough resistance to the mechanical shock and abrasion. The percent drug content of tablets was found to be in between $94.23 \pm 0.03$ to $98.46 \pm 0.03$ $\%=$ of levodropropizine, which was within the acceptable limits. The results of physicochemical characters of levodropropizine tablets were shown in Table 3 .

\section{Table 3: Evaluation Of Post-compression Parameters}

\begin{tabular}{|c|c|c|c|c|c|c|c|c|}
\hline $\begin{array}{c}\text { Batch } \\
\text { Code }\end{array}$ & $\begin{array}{c}\text { Thickness } \\
(\mathrm{mm}) \\
(\mathrm{n}=6)\end{array}$ & $\begin{array}{c}\text { Diameter } \\
(\mathrm{mm}) \\
(\mathrm{n}=6)\end{array}$ & $\begin{array}{c}\text { Weight } \\
\text { variation } \\
(\mathrm{mg})(\mathrm{n}=20)\end{array}$ & $\begin{array}{c}\text { Hardness } \\
\left(\mathrm{kg} / \mathrm{cm}^{2}\right) \\
(\mathrm{n}=6)\end{array}$ & $\begin{array}{c}\text { Friability } \\
(\%) \\
(\mathrm{n}=20)\end{array}$ & $\begin{array}{c}\text { Drug } \\
\text { content } \\
(\%) \\
(\mathrm{n}=3)\end{array}$ & $\begin{array}{c}\text { Buoyancy } \\
\text { Lag Time } \\
(\mathrm{sec}) \\
(\mathrm{n}=3)\end{array}$ & $\begin{array}{c}\text { Total } \\
\text { Floating } \\
\text { Time }(\mathrm{hrs}) \\
(\mathrm{n}=3)\end{array}$ \\
\hline F1 & $3.52 \pm 0.02$ & $5.35 \pm 0.05$ & $380 \pm 5 \%$ & $4.5 \pm 0.02$ & $0.28 \pm 0.05$ & $97.01 \pm 0.02$ & 30 & $>24$ \\
\hline F2 & $3.53 \pm 0.01$ & $5.35 \pm 0.02$ & $377 \pm 5 \%$ & $5.0 \pm 0.04$ & $0.5 \pm 0.03$ & $97.91 \pm 0.04$ & 12 & $>24$ \\
\hline F3 & $3.45 \pm 0.07$ & $5.32 \pm 0.04$ & $378 \pm 5 \%$ & $5.7 \pm 0.06$ & $0.24 \pm 0.04$ & $98.42 \pm 0.05$ & 04 & $>24$ \\
\hline F4 & $3.40 \pm 0.08$ & $5.36 \pm 0.04$ & $379 \pm 5 \%$ & $4.5 \pm 0.01$ & $0.52 \pm 0.06$ & $98.24 \pm 0.09$ & 118 & $>24$ \\
\hline F5 & $3.41 \pm 0.03$ & $5.33 \pm 0.02$ & $378 \pm 5 \%$ & $5.1 \pm 0.04$ & $0.23 \pm 0.01$ & $97.36 \pm 0.05$ & 72 & $>24$ \\
\hline F6 & $3.43 \pm 0.05$ & $5.33 \pm 0.09$ & $380 \pm 5 \%$ & $5.2 \pm 0.03$ & $0.6 \pm 0.08$ & $98.27 \pm 0.06$ & 12 & $>24$ \\
\hline F7 & $3.37 \pm 0.03$ & $5.36 \pm 0.07$ & $379 \pm 5 \%$ & $4.8 \pm 0.05$ & $0.5 \pm 0.04$ & $98.37 \pm 0.04$ & 136 & $>24$ \\
\hline F8 & $3.40 \pm 0.03$ & $5.34 \pm 0.07$ & $374 \pm 5 \%$ & $4.7 \pm 0.06$ & $0.67 \pm 0.06$ & $98.46 \pm 0.03$ & 48 & $>24$ \\
\hline F9 & $3.52 \pm 0.02$ & $5.35 \pm 0.06$ & $379 \pm 5 \%$ & $4.9 \pm 0.04$ & $0.5 \pm 0.02$ & $94.23 \pm 0.03$ & 82 & $>24$ \\
\hline F10 & $3.53 \pm 0.04$ & $5.33 \pm 0.02$ & $376 \pm 5 \%$ & $5.3 \pm 0.08$ & $0.64 \pm 0.04$ & $97.67 \pm 0.02$ & 32 & $>24$ \\
\hline
\end{tabular}




\section{In vitro Buoyancy Study:}

On immersion in $0.1 \mathrm{~N} \mathrm{HCl}$ solution $\mathrm{pH}(1.2)$ at $37^{\circ} \mathrm{C}$, the tablets floated and remained buoyant. The results of Buoyancy study was shown in Table 3. From the results it can be concluded that the Formulations containing drug and different viscosity grades of HPMC along with gas generating agent, the floating lag time was found to be in between $4 \mathrm{sec}$ to $120 \mathrm{sec}$ and remained under floating conditions for $>24 \mathrm{~h}$. This showed good Buoyancy lag time (BLT) and Total floating time (TFT).

\section{Swelling Study:}

Swelling study was performed on all the batches from F1 to F10 for $24 \mathrm{~h}$. From the results it was concluded that swelling increases as the time passes because the polymer gradually absorb water due to hydrophilicity of polymer. The outermost hydrophilic polymer hydrates and swells and a gel barrier are formed at the outer surface. As the gelatinous layer progressively dissolves and/or is dispersed, the hydration swelling release process is continuous towards new exposed surfaces, thus maintaining the integrity of the dosage form. In the present study, the higher swelling index was found for tablets of batch F3 containing HPMC $\mathrm{K}_{4} \mathrm{M}$.

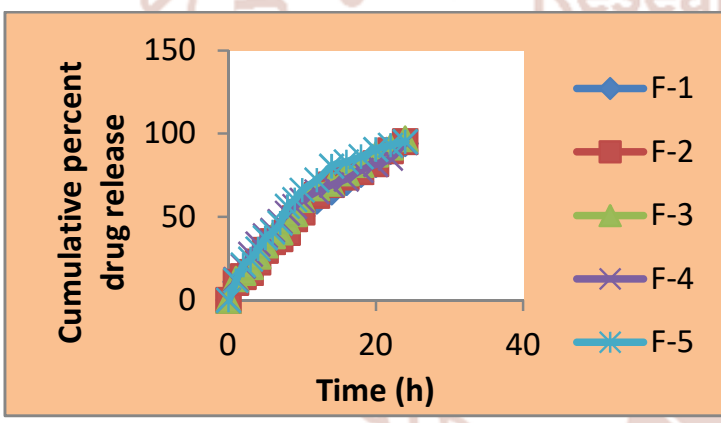

(a) Formulation F1- F5

\section{IN VITRO DISSOLUTION STUDIES:}

The in vitro release of all ten batches of floating tablets showed the release with an initial effect. In the first hour $\%$ drug released were $11.12 \%, 10.68 \%$, $12.82 \%, 12.58 \%, 11.91 \%, 10.7 \%, 11.02 \%, 10.58 \%$, $19.70 \%, 12.35 \%$ for F1, F2, F3, F4, F5, F6, F7, F8, F9 and F10 formulations respectively. HPMC polymers yielded a faster initial burst effect due to hydrophilic nature and fast hydration. Compared to viscosity of HPMC polymers the $\mathrm{K}_{4} \mathrm{M}$ is fastly hydrated and drug release is faster when compared to $\mathrm{K}_{15} \mathrm{M}$, where as $\mathrm{K}_{15} \mathrm{M}$ hydrated more rapidly than $\mathrm{K}_{100} \mathrm{M}$. So, F3 was found to release in a more controlled manner and it was selected as optimized formulation based on drug release $(97.14 \%)$ and floating lag time ( $4 \mathrm{sec})$. It concludes F3 had better controlled release than the other formulations.

From the results, it was observed that as the concentration of the polymers increased, there is a decrease in the drug release rates. An increase in polymer concentration causes increase in viscosity of the gel as well as the gel layer with longer diffusional path. This could cause a decrease in effective diffusion coefficient of the drug and a reduction in drug release rate

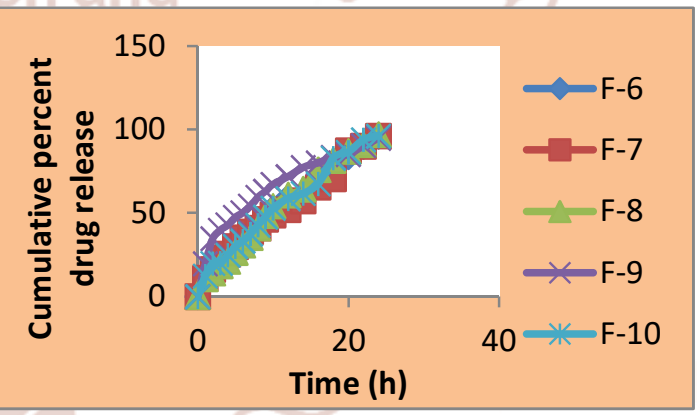

(b) Formulation F6- F10

Figure 1: Cumulative percent drug release Vs Time plots (Zero Order)

\section{DRUG RELEASE KINETICS:}

The kinetic values obtained for formulation F1 to F10 were shown in Table 4 . The values of in vitro release were attempted to fit into various mathematical models. Plots of Zero order, First order, Higuchi matrix, Korsmeyer and Peppas model.

The regression coefficients values for all formulations of zero order plots shows that except F4, F5 and F9 all the other formulations are supported by regression value. The regression coefficient values for all formulation of first order plots indicate that among all formulations F5 and F9 are supported by regression value. The results suggested that formulations F1, F2, F3, F6, F7, F8 and F10 fits zero order kinetics, formulation F5 \& F9 fits first order kinetics.

To ascertain the drug release mechanism the in vitro release data were also subjected to Higuchi equation. The calculated regression coefficient value for all formulations of Higuchi equation shows that all the formulations fits and supported by regression value. The results suggested that the calculated $r$ value for 
International Journal of Trend in Scientific Research and Development (IJTSRD) ISSN: 2456-6470

Higuchi plot were nearer to one (1) plot was linear suggesting that the drug released by diffusion mechanism. The regression coefficients values for all formulation of Peppas - korsmeyer shows that all the formulations fits and show linearity and this plot confirms that drug released by diffusion mechanism. Peppas - korsmeyer equation was given as,

$$
\% \mathbf{R}=\mathbf{k t}
$$

The slope ' $\mathrm{n}$ ' value for $\mathrm{F} 1$ to $\mathrm{F} 10$ formulations was found to be $0.712,0.751,0.694,0.611,0.672,0.689$, $0.679,0.765,0.457$ and 0.667 which indicates that the release were found to be $>0.45$ and $<0.89$ indicating that the drug release is governed by nonfickian diffusion mechanism

Table 4: Regression Analysis of formulations (F1 - F10) of Levodropropizine floating tablets :

\begin{tabular}{|c|c|c|c|c|}
\hline \multirow{2}{*}{ Batches } & \multicolumn{3}{|c|}{$\mathrm{r}^{2}$} \\
\cline { 2 - 5 } & Zero order & First order & Higuchi & Korsmeyer-Peppas \\
\hline F1 & 0.984 & 0.929 & 0.986 & 0.989 \\
\hline F2 & 0.974 & 0.930 & 0.987 & 0.984 \\
\hline F3 & 0.964 & 0.924 & 0.990 & 0.987 \\
\hline F4 & 0.932 & 0.922 & 0.995 & 0.991 \\
\hline F5 & 0.924 & 0.989 & 0.983 & 0.986 \\
\hline F6 & 0.981 & 0.877 & 0.984 & 0.995 \\
\hline F7 & 0.982 & 0.856 & 0.970 & 0.992 \\
\hline F8 & 0.983 & 0.909 & 0.983 & 0.984 \\
\hline F9 & 0.879 & 0.967 & 0.990 & 0.984 \\
\hline F10 & 0.984 & 0.894 & 0.975 & 0.984 \\
\hline
\end{tabular}

\section{Stability Studies:}

The formulation $\mathrm{F} 3$ was selected for stability studies on the basis of their in vitro drug release, floating time studies. The stability studies were carried out at $40 \pm 2^{\circ} \mathrm{C} / 75 \pm 5 \%$ RH upto 3 months. At the end of every month the tablet were retested for physical appearance, percentage drug content, hardness, floating properties etc., The results obtained for the above are shown in Table 5. The results indicate that there is no change in the parameters evaluated and the formulation F3 was stable for 3 months.

Table 5: Stability studies of optimized F3 Formulation

\begin{tabular}{|c|c|c|c|c|c|c|}
\hline $\begin{array}{c}\text { Time } \\
\text { (months) }\end{array}$ & $\begin{array}{c}\text { Hardness } \\
\left(\mathrm{kg} / \mathrm{cm}^{2}\right)\end{array}$ & $\begin{array}{c}\text { Drug } \\
\text { Content(\%) }\end{array}$ & $\begin{array}{c}\text { Swelling } \\
\text { Index(\%) }\end{array}$ & $\begin{array}{c}\text { Floating Lag } \\
\text { Time(sec) }\end{array}$ & $\begin{array}{c}\text { Total } \\
\text { Floating } \\
\text { Time(h) }\end{array}$ & $\begin{array}{c}\text { Weight } \\
\text { variation } \\
\text { (mg) }\end{array}$ \\
\hline Initial & 5.7 & 98.42 & 150 & 04 & 24 & $378 \pm 5 \%$ \\
\hline 1 & 5.5 & 98.23 & 148 & 08 & 24 & $376 \pm 5 \%$ \\
\hline 2 & 5.4 & 97.78 & 147 & 12 & 24 & $376 \pm 5 \%$ \\
\hline 3 & 5.4 & 97.46 & 145 & 16 & 24 & $374 \pm 5 \%$ \\
\hline
\end{tabular}




\section{CONCLUSION:}

A successful attempt was made to formulate and evaluate controlled release floating tablets of Levodropropizine using different hydrophillic polymers. The Gastroretentive floating tablet of Levodropropizine $380 \mathrm{mg}$ was formulated as an approach to increase gastric residence time and thereby improve its bioavailability. All the prepared HBS formulations were evaluated for Hardness, Friability, Uniformity of weight, Drug content uniformity, Drug-polymer interaction, in vitro floating studies, in vitro drug release and Short term stability studies. The drug - polymer ratio, viscosity grades of HPMC, diluents and gas generating agents were found to influence the drug release and floating properties of the prepared HBS. Increase in polymer viscosity was found to retard the drug release from the HBS.

The in vitro dissolution profiles of all the HBS formulations of Levodropropizine were controlled over a period of $24 \mathrm{~h}$. Release of Levodropropizine from the formulations was found to follow zero order kinetics. The drug release data showed a good fit to Higuchi model indicating that diffusion is the predominant mechanism controlling the drug release. The value of diffusional exponent ' $n$ ' for the Korsmeyer equation suggested that the drug release was by non-fickian diffusion Mechanism. Among the various HBS formulations studied, formulation F3 prepared at drug polymer ratio of $1: 2$ with HPMC $\mathrm{K}_{4} \mathrm{M}$ and lactose, an optimum concentration of gas generating agents Sodium bicarbonate and citric acid exhibited good in vitro floating ability and controlled drug release over a period of $24 \mathrm{~h}$. Hence F3 was considered as promising formulation. The tablets of selected formulations were subjected for the stability study showed insignificant change in appearance, physical attributes, drug content and in vitro drug dissolution before and after stability study. It suggested that the tablets are found to be a stable throughout the study period. Thus it is concluded that HPMC $\mathrm{K}_{4} \mathrm{M}$, HPMC $\mathrm{K}_{15} \mathrm{M}$ and HPMC $\mathrm{K}_{100} \mathrm{M}$ can be successfully used in the formulation of Levodropropizine controlled release gastro retentive floating drug delivery system.

\section{REFERENCES:}

1. Sanjay Garg and Shringl Sharma, Gastro retentive drug delivery systems, Drug delivery oral, 2003, 160-166.

2. Aulton E. Pharmaceutics: The Science of Dosage Form Design. 2nd ed. Published by Living Stone C. Elsevier Science Ltd. 2002; pp 315 - 389.

3. Rouge N, Buri P, Doelker E. Drug absorption sites in the gastrointestinal tract and dosage forms for site-specific delivery. Int J Pharm 1996;136:11739.

4. Shweta Arora, Javed Ali, Alka Ahuja, Roop K Khar and Sanjula Baboota, Floating drug delivery system: A Review, AAPS PharmaSciTech,2005;6 (3):E372-E390.

5. Reddy L, Murthy R. Floating dosage systems in drug delivery. Crit Rev Ther Drug Carrier Syst 2002;19:553-85.

6. Sangekar S, Vadino WA, Chaudry I, Parr A, Beihn R, Digenis G. Evaluation of effect of food and specific gravity of tablets on gastric retention time. Int J Pharm1987; 35:187-91.

7. Hiton $\mathrm{AK}$, Desay $\mathrm{PB}$. In vitro and in vivo evaluation of an oral sustained release dosage form of amoxycilline trihydrate. Int $\mathrm{J}$ Pharm. 1992; 86: 79 -88.

8. Stockwell AF, Davis SS, Walekar SE. In vitro evaluation of alginate gel system as sustained release drug deliver systems. J Control Release. 1986; 3: $167-75$.

9. Fell J T, Whitehead L and Collet H. Prolonged gastric retention using floating dosage forms. Pharm Technol. 2000; 24(3): 82-90.

10. Despande A A, Rhodes C T, Shah N H and Malick A W. Controlled release drug delivery systems for prolong gastric residence: an overview. Drug.Dev.Ind.Pharm. 1996; 22(6): 531539.

11. Watanabe K. Preparation and evaluation of intragastric floating tablet having $\mathrm{pH}$ independent buoyancy and sustained release property. Arch.Pract.Pharm Yakuzaigaku. 1993; 53: 1-7.

12. Sing B N and Kim K H, Floating Drug Delivery Systems: an approach to oral controlled drug delivery via gastric retention. J.Control.Release; 2000; 63: 235-259. 
13. Timmermans J, Moes AJ. Factors controlling the buoyancy and gastric retention capabilities of floating matrix capsules: new data for reconsidering the controversy. J Pharm Sci 1994;83:18-24

14. Vyas SP, Roop KKhar. Controlled Drug Delivery Concepts and Advances. 1st ed. Delhi(India): Vallabh Prakashan; 2002. p. 257-61.

15. Ali J, Arora S, Ahuja A, Babbar AK, Sharma RK, Khar RK, et al. Formulation and development of hydrodynamically balanced system for metformin: In vitro and in vivo evaluation. Eur $\mathrm{J}$ of Pharmaceutics and Biopharmaceutics 2007; 67:196-201.

16. El-Kamel AH, Sokar MS, Al Gamal SS, Naggar VF. Preparation and Evaluation of Ketoprofen Floating Oral Delivery System. Int $\mathbf{J}$ Pharmaceutics 2001; 220: 13-21.

17. Ramesh bomma, Rongola appala swamy naidu, Madhusudhan rao yamsani, Kishan veerabrahma, Development and evaluation of gastroretentive norfloxacin floating tablets, Acta Pharm.2009:59:211-221.

18. Gan Lin Chen, Wei Hua Hao, In vitro performance of floating sustained release capsules of verapamil. Drug Dev Ind Pharm; 24(11): 10671072. 1998

19. R Garg, GD Gupta, Progress in controlled gastro retentive delivery systems, Tropical journal of pharmaceutical research, 2008; 7(3): 1055-1066

20. Patel VF, Patel NM, Yeole PG. Studies on formulation and evaluation of ranitidine floating tablets. Indian J Pharm Sci 2005;67(6):703-9.

21. Sheth PR, Tossounian J. The hydrodynamically balanced system (HBS TM): a novel drug delivery system for oral use. Drug Dev Ind Pharm 1984;10:313-39.

22. Raymond C Rowe, Paul J Sheskey, Paul J Weller, Hand Book of Pharmaceutical Excipients published by pharmaceutical press, Fourth ed, 2003; 111-115, 346-349.

23. Sameer singh, kalpana prajapati, A.k pathak, A mishra . Formulation and evaluation of Floating tablet of captopril 2011, 3(1), 333-341.

24. Dave BS, Amin AF and Patel MM: Gastro retentive drug delivery system of ranitidine hydrochloride: Formulation and in vitro evaluation. AAPS PharmSciTech 2004; 5(2): 1520.
25. Brahmankar DM, Jaiswal SB. Biopharmaceutics and Pharmacokinetics. Vallabh Prakashan; Delhi; 2005; 53-63

26. AV Mayavanshi and SS Gajjar, Floating drug delivery systems to increase gastric retention of drugs: A review, Research J. Pharm. and Tech, 2008; 1(4): 1-4.

27. Cooper J, Gun C, Carter SJ Powder Flow and Compaction. Tutorial New Delhi: CBS Publishers; 1986. p.211-33.

28. Shah D, Shah Y, Ramprashad M. Development and evaluation of controlled release diltiazem hydrochloride microparticles using cross-linked poly vinyl- alcohol. Drug Dev Ind Pharm 1997;23(6):56774.

29. Lieberman HA, Lachman L, Schwartz JB. Pharmaceutical Dosage Forms: Tablet, Vol 1. New York; Marcel Dekker; 2005.

30. Kumar R, Philip A. Gastroretentive Dosage forms for prolonging gastric residence time. Int J Pharm Med 2007; 21 (2): 157-71. 